\title{
Trilha interpretativa como instrumento de comunicação ambiental: uma experiência no Parque Natural Municipal dos Morros, Santa Maria (RS, Brasil)
}

\section{Interpretive trail as an instrument of environmental communication: an experience in the Morros Municipal Natural Park, Santa Maria (RS, Brazil)}

Marina Deon Ferrarese, Letícia Ramires Corrêa, Guilherme Lul da Rocha, Rafael Camilo Ribeiro

RESUMO: O trabalho buscou a interpretação ambiental por meio da realização de Trilhas Interpretativas no Parque Natural Municipal do Morros. Foi utilizada a entrevista semiestruturada que constatou cinco pontos-chave para os visitantes: natureza, mirante, caminhada/aventura, conhecimento e interação social.

PALAVRAS-CHAVE: Interpretação ambiental; Unidade de Conservação; Trilha Guiada; Mirantes.

\section{ABSTRACT}

The work sought the environmental interpretation through the realization of Interpretive Trails in the Municipal Natural Park of Morros. It was used the semi-structured interview that found five key points for visitors: nature, lookout, hiking / adventure, knowledge and social interaction.

KEYWORDS: Environmental Interpretation; Conservation Unit; Guided Trail; Lookouts.

\section{Considerações iniciais}

Diante da atual crise socioambiental, as iniciativas de sustentabilidade vêm trilhando um caminho mais equilibrado entre a natureza e o homem. Porém, a sustentabilidade aqui entendida busca uma articulação entre as três dimensões que fazem do Planeta Terra o que ele é.

A dimensão que se refere a sociedade, a que abrange a natureza e que representa a economia. Tais dimensões para devem relacionar-se de maneira uniforme, sem disparidades e excessos causados pela Modernidade. Tais excessos acumulados por centenas de anos construíram uma anomalia nas dimensões que baseiam a sustentabilidade, principalmente na dimensão da natureza. Com exploração desenfreada, o 
conceito de desenvolvimento sustentável, mascarando os danos irreversíveis, atrasam o fim provável.

Em relação a dimensão da sociedade a crise ecológica está diretamente conectada com a pobreza da metade da população mundial. Justamente pela perda da biodiversidade e da diversidade cultural oprimida pela aceleração imposta pela Modernidade. O bem-estar não corresponde a um elevado grau de desenvolvimento. A posição desenvolvimentista baseiase em leis que não conversam com as leis da natureza, é como se o tempo do desenvolvimento fosse diferente da natureza, é retirado muito mais do que ela pode se recuperar. O desenvolvimento sustentável tem outro olhar trazendo uma transformação entre as relações entre economia, ecologia e ética (BOADA; TOLEDO, 2003)

É importante para construir a sustentabilidade que se pense em projetos de médio a longo prazo, para que assim, se considere o tempo de renovação da natureza. Não há um projeto perfeito, dizendo como devemos fazer ou por onde devemos ir, encontrar o caminho da sustentabilidade requer mudanças profundas. Em busca do desenvolvimento sustentável é necessário abandonar os procedimentos lineares de análise e começar a pensar em mecanismos circulares. O enfoque sistêmico permite compreender 0 que acontece em uma parte do sistema afeta todo o resto. Utilizar o enfoque sistêmico é compreender a complexidade do mundo vivo (NOVO,2006).

Nesse contexto, destaca-se a Trilha Interpretativa que consiste em um instrumento de revelação da natureza e auxilia na construção da consciência ambiental, além disso, constitui-se como importante ferramenta no manejo das Unidades de Conservação (UCs), instigando pensamentos e reflexões sobre a ação e de cada participante a experiência em meio natural, nas unidades de Conservação (SANTOS et al.,2012; VASCONCELLOS,2004).

Desta forma, justifica-se este trabalho com a busca da aproximação da população com o Parque Natural Municipal dos Morros (PNMM) por meio dos atrativos de sua paisagem natural, possibilitando a divulgação da importância dessa Unidade de Conservação (UC). Associa-se a isso, a necessidade de implementar a interpretação ambiental (Trilhas Interpretativas) no PNMM como previsto em seu Plano de Manejo.

As questões centrais desta pesquisa são: como as Trilhas Interpretativas guiadas contribuem para a compreensão da percepção ambiental dos visitantes do Parque Natural Municipal dos Morros? A realização dessas trilhas possibilita a sensibilização ambiental e divulgação da importância do PNMM? Objetiva-se introduzir o trabalho de Interpretação Ambiental na área do PNMM, por meio da realização da Trilha Interpretativa Guiada Bandeirantes da Serra (TIGBS). Assim, busca-se a compreensão da percepção dos visitantes antes (expectativas) e depois da participação dessas trilhas (realidade vivenciada).

Portanto, almeja-se contribuir para a melhoria de futuras repetições da TIGBS, bem como, na realização de outras trilhas desta Unidade de Conservação. Além disso, visa-se sensibilizar a população participante em relação a preservação do meio ambiente e também, enfatizar a importância 
de UCs mediante o contato com o meio natural no PNMM e da transmissão do conhecimento científico de forma acessível e prática, proporcionados durante a experiência prática da Trilha Interpretativa.

\section{Desenvolvimento: referencial teórico}

\section{A paisagem como fio condutor para a conservação}

Desde antes de ser ciência a paisagem demonstra uma relevante contribuição na leitura do espaço. Para isso, toma-se como abordagem a perspectiva monista de analisar a paisagem, com o objetivo de tomá-la em sua unidade. Tal perspectiva nasce para contrapor o Positivismo do século XIX criado na França por Augusto Comte, que buscava a ciência puramente lógica. A perspectiva monista por sua vez busca a totalidade, ou seja, algo só é o que é se considerar todas as suas dimensões. Diante disso, tomamos o nascimento da paisagem como ciência juntamente como a perspectiva monista na Alemanha com Alexander von Humboldt, com o movimento Romântico na época era uma resposta ao dualismo Cartesiano. Com Humboldt considerar as distintas formas de percepção, unindo as dimensões sociais, culturais, naturais e econômicas, era a única forma de compreender a paisagem em sua totalidade (TORRES; BASSOLS, 2009). A perspectiva monista ousava em considerar o pensar e o sentir, ou seja, considerar não só a objetividade, mas também a subjetividade das coisas.

Desse modo, Casseti (2005, s/p) aborda a fisiologia da paisagem, que seria a condição atual do relevo "considerando os processos morfodinâmicos, as transformações produzidas pelo homem e as derivações resultantes (processos erosionais, assoreamento)". Em vista disso, compreende-se que a fisiologia da paisagem analisa as condições atuais do relevo, mas considera os processos que transformaram a paisagem, com isso pode-se compreender de melhor forma os processos da paisagem, pois ao avistar uma paisagem de beleza cênica relevante, como Serras e florestas, ao se trabalhar a Interpretação Ambiental deve-se despertar a curiosidade do indivíduo em saber mais sobre o que seus olhos estão enxergando. Ele deve sair da Trilha com anseio de compreender os processos formadores desta paisagem. Desta forma, (TRICART, 1978 apud CASSETI, 2005, s/p), define o conceito de paisagem que "abrange uma realidade que reflete as profundas relações, frequentemente não visíveis, entre seus elementos".

Com esta perspectiva de manter estas paisagens intactas para as gerações futuras entra-se em discussão a preservação destas áreas. $O$ interesse por preservar ambientes naturais surge no séc. XIX nos EUA, com a criação do Parque Nacional de Yellowstone. Esse modelo americano de natureza intocada influenciou muitos sistemas de conservação no mundo todo principalmente com o modelo de Parques, como é o exemplo das UCs brasileiras.

Para isso, buscaram-se medidas dentro da lei que assegurasse a preservação de todas as formas de vida (THOMAS et al., 2011), e foi criado - Sistema Nacional de Unidades de Conservação da Natureza (SNUC, Lei n-9.985/2000), que busca estabelecer critérios e normas para a criação, 
implantação e gestão das Unidades de Conservação (UCs) na esfera nacional, estadual e municipal. As UCs são espaços territoriais que devido suas características naturais relevantes visam à conservação, sendo assim, instituídas legalmente pelo Poder Público.

O SNUC divide as UCs em duas categorias, conforme seus objetivos de proteção, de acordo com a Lei no 9.985 de 2000, assim define o grupo das UCs de Uso Sustentável, que engloba áreas que visam conciliar a conservação da natureza com o uso sustentável de parte de seus recursos naturais. E também, há categoria das UCs de Proteção Integral que são áreas que têm como objetivo básico preservar a natureza, os ecossistemas livres da interferência humana, admitindo-se apenas o uso indireto dos recursos naturais, ou seja, não envolvendo consumo, coleta, ou destruição dos recursos naturais.

Nesse contexto, o PNMM foi instituído como UC de Proteção Integral, na categoria Parque Natural Municipal, objetivando a preservação dos ecossistemas naturais de grande relevância ecológica e cênica que se constituem em remanescentes da Mata Atlântica. Conjuntamente, busca-se o desenvolvimento de atividades de educação e interpretação ambiental, de recreação em contato com a natureza e de turismo ecológico (DECRETO № 38.814, 1998; SNUC, Lei $\mathrm{n}$-9.985/2000; SANTA MARIA, 2016 B GEOPROPEC,2013 C).

A área do PNMM abrange tanto a zona urbana como a rural de Santa Maria, RS. Encontra-se entre as unidades geomorfológicas da Depressão Periférica Sul rio-grandense e dos Planaltos e Chapadas da Bacia do Paraná (ROSS, 1989). E uma transição usualmente chamada de Rebordo do Planalto. Região marcada pela transição dos remanescentes da Mata Atlântica que ocupa o rebordo dissecado do Planalto, para os campos e florestas ciliares da Depressão Central em Santa Maria (MARCHIORI, 2009; IBGE, 2012; LÖBLER; SCCOTI; WERLANG, 2015). Assim, essa heterogeneidade ambiental, culmina em uma alta biodiversidade local e em grande valor paisagístico.

Somando a tudo isso, o PNMM também está inserido na Zona Núcleo da Reserva da Biosfera da Mata Atlântica (MARCUZZO, PAGEL; CHIAPPETTI, 1998; BRASIL 2002), e em área prioritária para a conservação (MINISTÉRIO DO MEIO AMBIENTE, 2000). Desta forma, salienta-se a importância da preservação da área do PNMM, desenvolvimento de atividades de educação e interpretação ambiental e de turismo ecológico.

\section{O Grupo Bandeirantes da Serra e a área do PNMM}

O Grupo Bandeirantes da Serra, desde sua criação em 1991, desenvolve atividades de montanhismo na atual área do PNMM. A nominação do Grupo faz referência aos antigos bandeirantes que percorriam longos trajetos a pé pelas Serras de São Martinho e do Pinhal, também, devido ao pioneirismo em atividades verticais.

A área que atualmente constitui o PNMM é associada culturalmente à prática do montanhismo, devido à atuação há anos do GBS, por meio de 
caminhadas, campismo, escalada e rapel, dentre outras atividades que desenvolve. Esse Grupo preza pela ética no montanhismo e em todas suas atividades, busca atuar com mínimos impactos ao meio ambiente considerando a Declaração do Tirol (2002) e Código Brasileiro de ética na escalada (1993).

$\mathrm{Na}$ área do PNMM, o GBS desenvolve atividades que visam preservar o meio ambiente, auxiliar na fiscalização de irregularidades nas questões ambientais e de acesso à área, atuar interligando os ramos de turismo de aventura, ecoturismo e educação ambiental conforme o Decreto Executivo n. 0012, de 11 fevereiro de 2016. Assim, o GBS realiza trilhas abertas à população, buscando mostrar a importância da instituição do PNMM. Através do conhecimento da UC, visa chamar a atenção para a exuberante natureza existente nos morros da cidade de Santa Maria, assim, objetiva sensibilizar as pessoas em prol da preservação do meio ambiente.

\section{Trilhas Interpretativas: os caminhos que provocam}

Desde os tempos mais remotos o ser humano utiliza trilhas para deslocar-se, seja para transporte, lazer, ou para atividades físicas em meio a natureza. Além disso, podem ser utilizadas com função educativa a fim de buscar em um caminho em meio à natureza, contemplação e descanso da rotina agitada dos grandes centros urbanos (PROJETO DOCES MATAS, 2002) e também aprender sobre o meio ambiente, com a natureza. Hoje as trilhas tomam um sentido ainda mais educacional e tornam-se aliadas da sustentabilidade, com a prática da Interpretação Ambiental. Seu princípio parte do contato direto com a natureza, da sensibilização e da tradução das informações para o visitante, de forma atrativa e recreativa.

Nesse sentido, a realização da TIGBS permite o contato com 0 ambiente natural, a transmissão de conhecimento científico de forma acessível por meio da utilização de comparações, de elementos existentes na trilha e de palavras cotidianas. Assim a atividade prática da trilha, é conjugada as observações momentâneas do meio ambiente, principalmente, nos pontos de parada da referida trilha. Tilden (1957, p.3), destaca que devido a esse contato direto com a natureza a interpretação ambiental é uma ferramenta diferenciada do ensino formal das salas de aulas:

\footnotetext{
$\mathrm{Na}$ maior parte desses locais (tesouros, bens patrimoniais) 0 visitante é exposto, por vontade própria, a um tipo de educação eletiva/opcional que é, em muitos aspectos, superior àquela da sala de aula, porque nela ele se encontra com a "coisa em si" - seja uma maravilha da natureza ou da criação humana
}

Seguindo o Manual de Introdução à Interpretação Ambiental, há três métodos de Interpretação de Trilhas: autoguiada com painéis autoguiada com roteiros; guiada com a presença de um intérprete. Nesta última categoria enquadra-se a TIGBS (Figura 1), compreendida neste estudo, a qual foi conduzida por condutores capacitados do Grupo Bandeirantes da 
Serra. A efetivação dessa trilha contou também, com o auxílio de integrantes do GBS que colaboram na organização, logística, em nas explicações ao longo da realização da atividade.

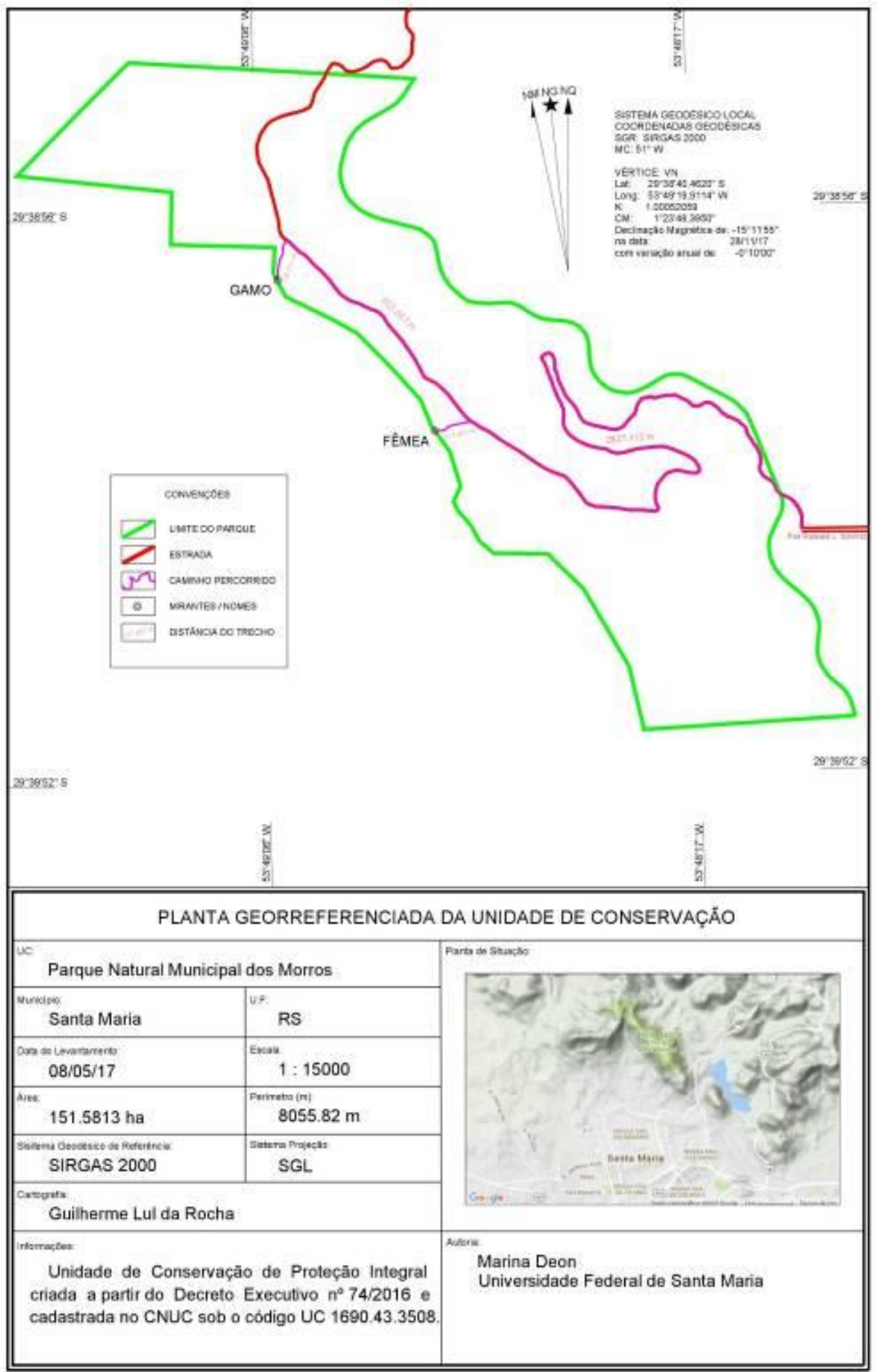

Figura 1: Localização da Trilha interpretativa Guiada Bandeirantes da Serra no Parque Natural Municipal dos Morros, Santa Maria, RS, BR. Fonte: Autores, 2018

Figure 1: Location of the Bandeirantes da Serra Guided Interpretive Trail in the Morros Municipal Natural Park, Santa Maria, RS, Brazil. Source: Authors, 2018. 
A trilha guiada por intérprete é importante por trazer um maior envolvimento com o público, sendo possível adequar o discurso para cada grupo, ou seja, se um grupo de visitantes está mais disperso o intérprete é capaz de atrair os dispersos alterando o tom de voz ou destacando uma paisagem, também respeita o ritmo de cada grupo.

Porém, a formação do intérprete é fundamental para o sucesso de uma trilha guiada, pois é ele que irá traduzir a linguagem da natureza para o visitante de maneira provocativa e prazerosa, como o Projeto Doces Matas (2002, p.77) ressalta as vantagens da trilha guiada:

\begin{abstract}
A trilha guiada exige a presença do Intérprete. Ele precisa estar sempre atento para envolver o visitante, estimulando-o a observar, sentir, experimentar e refletir a respeito do tema interpretativo, que está sendo apresentado. Uma das grandes vantagens dessa modalidade de trilha é o envolvimento entre as pessoas e o próprio Intérprete, possibilitando o diálogo, a troca de experiências, etc. Em outras palavras, uma trilha interpretativa guiada deve ser dinâmica, envolvendo a participação de todos.
\end{abstract}

Compreende-se que as trilhas guiadas "são meios para ajudar o visitante a entender e curtir esses fenômenos em sua totalidade" (TILDEN,1957, p.33), e são muito importantes para a provocação dos visitantes. Caso seja realizado com sucesso, uma trilha guiada pode despertar a curiosidade do grupo para elementos da natureza e suas conexões, de forma que ele saia da trilha com anseio de saber mais.

A modalidade de trilha guiada tem uma abrangência menor em relação a autoguiada por ter a necessidade de limitar o número de pessoas que formarão o grupo. Como toda e qualquer modalidade interpretativa, existem potencialidades e limites.

\title{
Material e Métodos
}

Em relação ao desenvolvimento utilizou-se uma abordagem sistêmica que auxilia a compreensão a paisagem do PNMM como uma unidade, com todas as suas partes e correlações, de tal forma que o visitante percebe que a natureza e o homem são indissociáveis. Sendo que, o último transforma e se apropria da natureza e também é transformado por ela. Assim, a presente pesquisa se desenvolveu nessa perspectiva monista ${ }^{1}$.

Para efetuar este trabalho, em um primeiro momento foi escolhido um percurso, no Parque Natural Municipal dos Morros, constituído em parte pelo trajeto proveniente dos usos anteriores à criação dessa UC. Essa porção inicial do trajeto é conhecida como Estrada Bandeirantes da Serra e usada como de acesso principal a área do morro desde a sua aquisição pelo antigo dono dessa área. Somando-se a essa parte, um fragmento da Trilha do Ramal Norte, que liga a Estrada Bandeirante da Serra aos Mirantes da Fêmea e do Gamo. Assim, constituiu-se o percurso da Trilha Bandeirantes 
da Serra, adaptada à interpretação ambiental e denominada Trilha Interpretativa Guiada Bandeirantes da Serra percorrida nesta pesquisa.

Nessa pesquisa, a trilha é considerada como um instrumento de manejo, para os gestores do PNMM, além de propiciar a conexão dos visitantes com a natureza, instigando pensamentos e reflexões sobre a ação e de cada participante perante essa vivência na Unidades de Conservação (VASCONCELLOS, 2004).

Pode-se classificar uma trilha de acordo com a sua função, forma, e o seu grau de dificuldade. O percurso total da TIGBS possui 3,877 (ida) de extensão, assim, considerada uma trilha longa. A mesma é classificada quanto à forma como linear, ligando a porção com menor elevação ao topo do morro (ANDRADE, W. J.; ROCHA, R. F., 2008). A porção inicial dessa trilha, denominada como Estrada Bandeirantes da Serra, abrange a estrada de acesso principal ao PNMM, com média de $4 \mathrm{~m}$ de largura, e aproximadamente $2.100 \mathrm{~m}$ comprimento, não pavimentada, com predomínio de vegetação arbórea e declividade média de 7,72\% (GEOPROPEC, 2013 A). Somando-se a essa porção, $1.770 \mathrm{~m}$ de extensão da Trilha Norte, com declividade média de cerca de 1,23\%, capacidade para um público de 64 pessoas, concomitantemente (GEOPROPEC, 2013 B.), caracterizada por uma região predominantemente plana e de vegetação campestre, o topo do morro.

Considerando o proposto por Dias et al. (1986), a TIGBS com aproximadamente $8,95 \%$ de declividade média é categorizada em intensidade leve (entre $0 \%$ e $10 \%$ de declividade média). Além disso, atentando o proposto por Dias et al. (1986) a TIGBS se enquadra no Grau A quanto a realização de atividades durante o percurso, por não exigir preparo físico dos participantes, proporcionando um passeio para admiração dos elementos da paisagem.

Sabe-se que a Trilha Interpretativa consiste em um instrumento de revelação da natureza ao visitante, buscando a provocação do indivíduo que de certa forma auxilia na construção da sua consciência ambiental (SANTOS et al., 2012). Nesta pesquisa houve a adaptação da Trilha Bandeirantes da Serra (Estrada Bandeirantes da Serra e fragmento da trilha do Ramal Norte) para a função de Trilha Interpretativa, mesmo que, sua dimensão seja maior do que a proposta por (ANDRADE; ROCHA, 2008).

O presente trabalho visa introduzir a Interpretação Ambiental no PNMM. Para isso, optou-se por utilizar A Trilha Bandeirantes da Serra já estabelecida na UC, com extensão maior do que a usual (em Trilhas Interpretativas), mas adaptada à realidade de acesso ao topo do morro, que se encontra em processo de melhorias. A Trilha Interpretativa Guiada Bandeirantes da Serra foi definida por incluir o acesso principal ao PNMM e por possibilitar a chegada aos Mirantes da Fêmea e Mirante do Gamo, localiza-se no perímetro da Zona Extensiva, e Zona Intensiva do PNMM.

Ao longo da TIGBS, foram definidos seis pontos de parada nos quais integrantes capacitados do GBS efetuaram explicações sobre temas relacionados ao meio ambiente (Unidades de Conservação, PNMM, 
esportes de aventura, relevo e formações geológicas, dentre outros). Os pontos de parada definidos foram:

Ponto 1- Entrada do PNMM: Enfatizou-se a importância do PNMM, categoria de UC. Além disso, expõem-se sobre a história e as atividades que o Grupo Bandeirantes da Serra desenvolve. Nesse ponto, os participantes voluntários receberam a entrevista semiestruturada e preencheram as questões 1 e 2.

Ponto 2- Vista para a barragem do DNOS: explicado sobre a importância dessa barragem, bem como, dos remanescentes da Mata Atlântica nos morros no Rebordo do Planalto, constituiu-se também, um momento de contemplação da paisagem.

Ponto 3- Ponto de parada Boulder Maracanã: definido para a explanação sobre o bloco de arenito rolado, conhecido como Boulder, que também designa uma modalidade de escalada para atletas mais experientes, efetuou-se um breve esclarecimento sobre essa e outras categorias de escalada, assim como a importância da ética nessa atividade.

Ponto 4- Topo do morro: realizada a explanação sobre os diferentes ambientes e biomas do RS, suas fisionomias e algumas espécies da flora observadas in loco.

Ponto 5 e 6 - Mirantes Fêmea e Gamo, respectivamente: efetua-se um momento com ênfase na contemplação da paisagem, explica-se sobre a origem do nome dos mirantes. No Mirante do Gamo os participantes efetuam o preenchimento da questão.

Utilizou-se a entrevista semiestruturada objetivando, conhecer os participantes, compreender as expectativas dos visitantes e os aspectos que mais lhes chamaram atenção (realidade por eles observada). A entrevista de caráter breve, visando estimular os participantes a responder, sendo composta por 3 questões:

\section{Qual sua profissão?}

2. Quais as suas expectativas com a realização desta trilha?

3. O que mais Ihe chamou atenção durante a realização desta trilha?

A entrevista foi disponibilizada aos participantes de maneira impressa, com fornecimento de caneta esferográfica para preenchimento. As questões 1 e 2 aplicadas antes dos participantes iniciarem o percurso da trilha e a questão 3 no final da mesma, com o objetivo de possibilitar a comparação dessas respostas.

Os visitantes das trilhas que se disponibilizaram a participar da entrevista, responderam a mesma por meio de escrita livre de palavras elou frases.

As datas de realização das três caminhadas na TIGBS foram divulgadas por meio de redes sociais pelas quais, também, foram indicadas informações sobre a trilha proposta, vestimenta adequada e itens 
importantes para levar durante a realização dessas atividades (como protetor solar, água, lanche). A participação foi feita por adesão voluntária, com inscrição on-line em uma das três caminhadas realizadas na mesma trilha em diferentes datas no ano de 2017. Todos os participantes estiveram cobertos pelo Seguro Ecotrip, durante o período de realização dessas atividades.

Os registros fotográficos utilizados neste trabalho, foram efetuados com câmera NIKON COOLPLIX L330.

Para a elaboração da Planta Georreferenciada da Unidadede Conservação utilizou-se o Software Datageosis Office (versão 7.5.10.3), desenvolvido para automação topográfica e geodésica.

\section{Resultados e discussão}

A referente pesquisa, entrevistou 30 pessoas, por adesão voluntária, durante as três caminhadas na TIGBS. Conhecer o público envolvido nestas atividades é de extrema relevância para o planejamento de novas Trilhas Interpretativas, assim como para a continuação da realização da TIGBS, pois para cada público deve haver um Programa de Interpretação. Definir um perfil do visitante que, segundo Ikemoto (2008, p.72-73) "permite conhecer as expectativas, as necessidades e os fatores que aumentam a qualidade da visita e enriquecem a experiência do turista".

No caso desta pesquisa $15 \%$ dos visitantes são estudantes de ensino superior, o que se justifica por Santa Maria ser uma cidade universitária e com alta taxa de escolarização (IBGE, 2017).

Assim como, os $9 \%$ que são professores. O que relaciona também com a importância do PNMM como um espaço de lazer e de construção de conhecimento para a comunidade de Santa Maria, disseminando a importância das Unidades de Conservação.

Objetivou-se descobrir o que o visitante esperava antes de percorrer a TIGBS e o que eles perceberam após a realização da TIGBS, com o objetivo de analisar o quanto a trilha foi transformadora para os participantes e de estabelecer quais aspectos que se destacaram nessa percepção.

Ressalta-se 5 pontos-chave que compreenderam as palavras mais citadas nas respostas dos entrevistados: natureza, mirante, caminhada/aventura, conhecimento e interação social (Gráfico 1). Desta forma, observa-se que os visitantes superam as expectativas no que se refere a natureza, o que pode ser explicado devido à grande beleza natural da paisagem do PNMM, que se destaca, chamando muito a atenção dos visitantes. Além disso, possivelmente atrelado as explicações que foram explanadas pelos integrantes capacitados do GBS, principalmente nos pontos de parada da trilha e eventualmente no decorrer da mesma sobre: a natureza, Unidade de conservação, biomas, flora, formações geológicas, esporte de aventura, e demais questões levantadas pelos participantes. 
Gráfico 1: comparação entre as expectativas e a realidade constatada pelos participantes da trilha (TIGBS) do PNMM.

Graph 1: comparison between the expectations and the reality verified by the participants of the PNMM (TIGBS) trail.

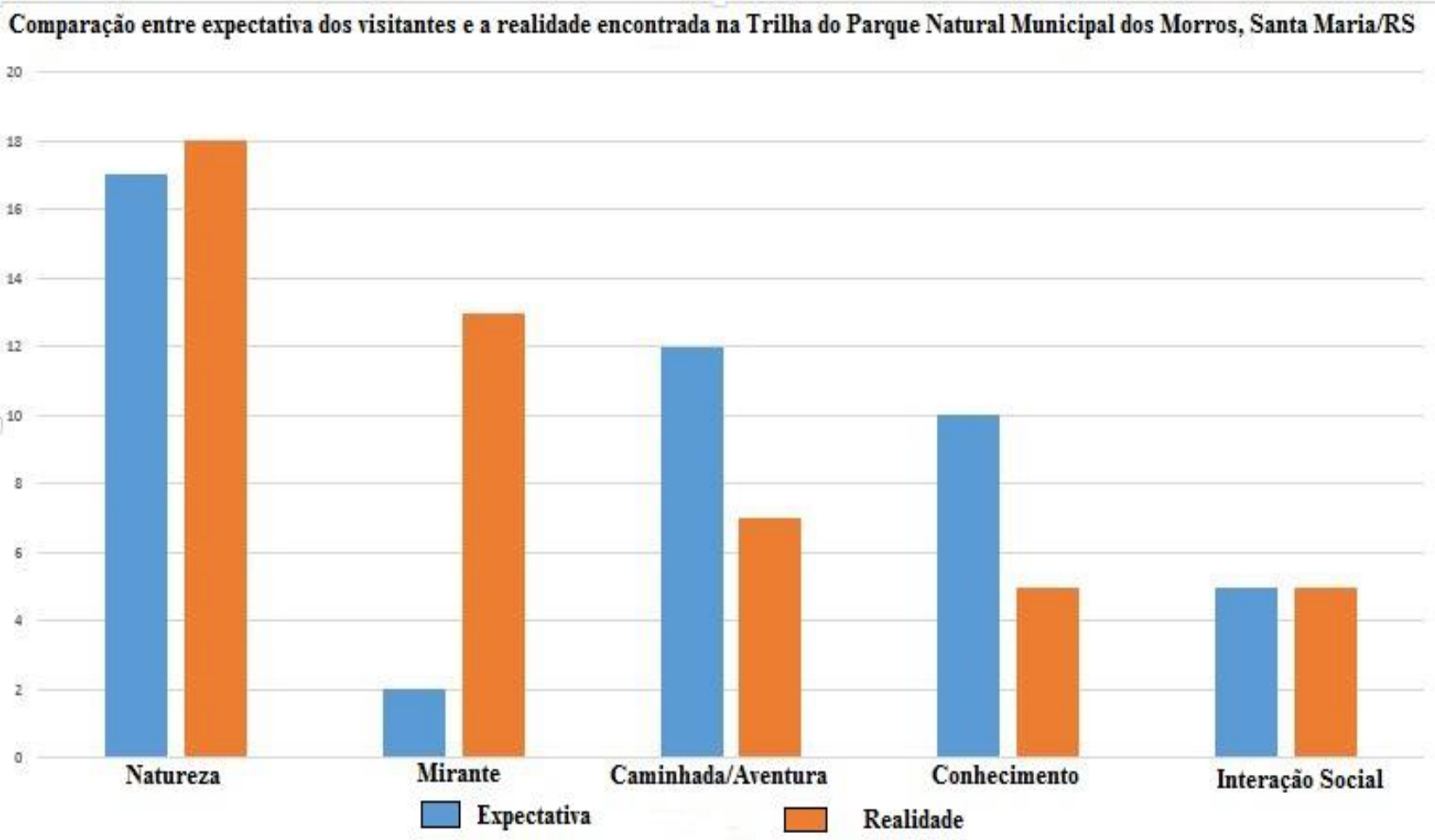

Fonte: Autor, 2018.

Source: Author, 2018.

Em relação aos mirantes as pessoas inicialmente apresentaram uma expectativa baixa, em relação a realidade encontrada. Este aspecto, pode estar relacionado com o fato da maioria dos visitantes entrevistados não conhecerem o PNMM e desconhecerem a presença de mirantes naturais que se destacam por propiciarem uma visão panorâmica. Também, justificase esse resultado considerando a teoria de Applenton que salienta o fator biológico instintivo de preferir ambientes que permitam uma visão mais ampla do meio. A grande satisfação pela realidade natural vivenciada nos mirantes (Figura 2), ressalta a importância do correto manejo deles, almejando a manutenção visão privilegiada da paisagem que eles proporcionam de modo conciliado com a preservação do meio ambiente desse local. Nota-se, contudo, que os mirantes são atrativos para os visitantes e podem contribuir para o chamamento de turistas e para a divulgação da beleza cênica da paisagem do PNMM. 


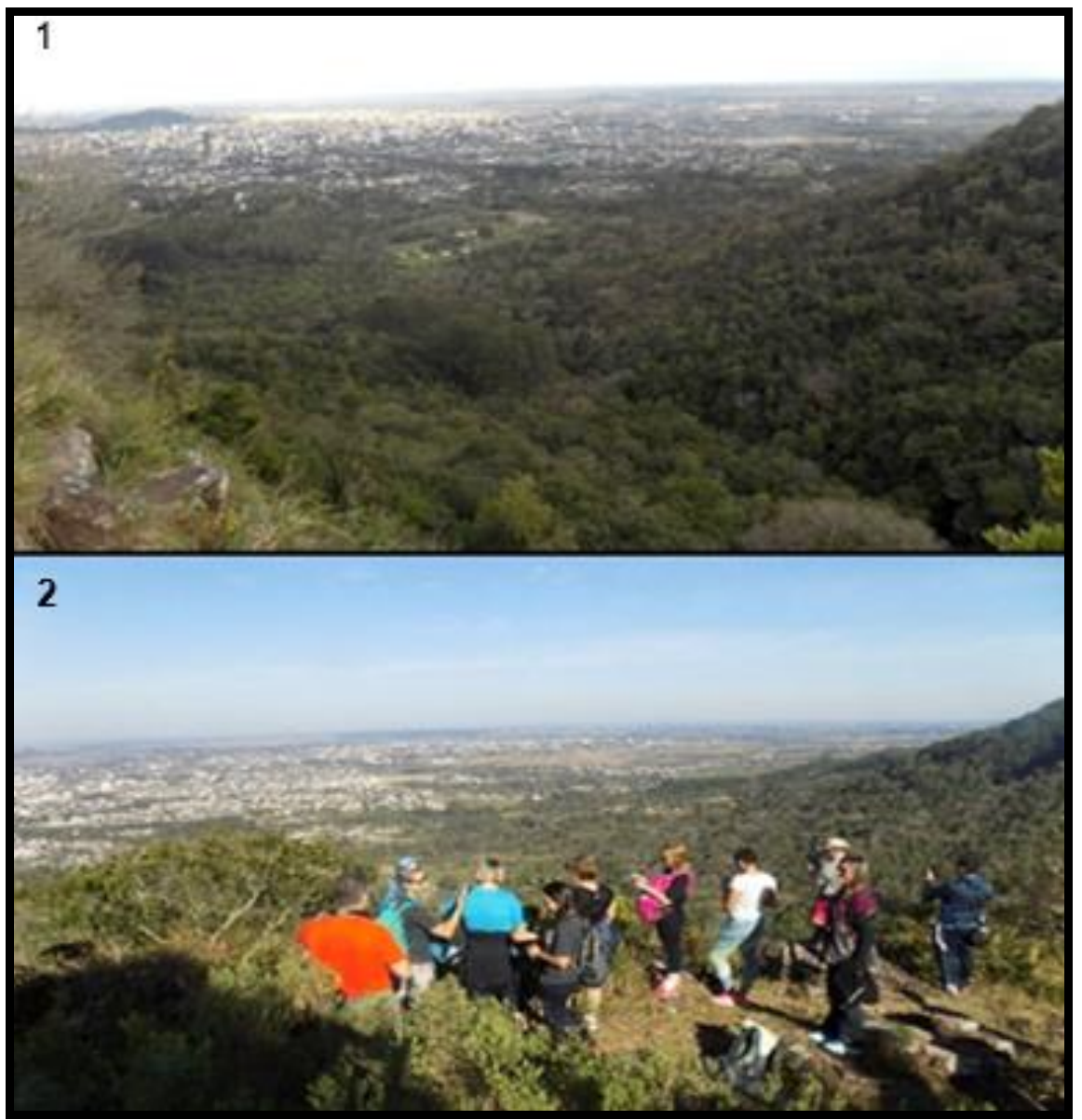

Figura 2- Vista panorâmica observada do mirante do Gamo no PNMM, RS (1). Grupo de visitantes em momento de contemplação da paisagem no mirante do Gamo, PNMM (2). Figure 2 - Observed panoramic view of Gamo viewpoint in RS, PNMM (1). Group of visitors at the moment of contemplation of the landscape in the gamo viewpoint, PNMM (2).

Fonte: Autor, 2017.

Source: Author, 2017.

No item caminhada/aventura a expectativa dos participantes foi maior do que sua opinião em relação a realidade vivenciada ao longo do percurso da Trilha Interpretativa Guiada Bandeirantes da Serra. Esse resultado aparece, provavelmente, em função da TIBS não possuir grandes obstáculos, apesar do trecho de inclinação média mais acentuada, a subida é efetuada serpenteando o declive. Esse apontamento é positivo, pois esse trajeto pode ser percorrido por público de larga variação de faixa etária. Isso demonstra, a partir da prática, que a realização do trajeto não necessita preparo físico intenso. Assim, indica que o trajeto em questão pode ser mantido na implantação de um Programa de Interpretação Ambiental.

Em relação ao conhecimento houve uma maior expectativa em relação ao que se mais destacou na vivência da TIBS que foi o encanto dos participantes ao contemplarem a natureza e a paisagem observadas durante a realização dessa trilha. Por fim, a em relação a interação social foram encontradas diferenças entre a expectativa e a realidade vivenciada, alguns participantes que almejavam formação de amizades, ou de conhecer novas pessoas, realizaram suas expectativas. 


\title{
Impactos para Conservação e Desdobramentos
}

Para esta pesquisa, lançou-se mão da análise da percepção ambiental dos visitantes da Trilha como instrumento para a gestão do Parque Natural Municipal dos Morros. Para isso, apropriou-se do conceito de Topofilia proposto por Tuan (1980), para analisar o que despertou mais interesse na paisagem conhecida, afim de apontar diretrizes para o planejamento e gestão, e construção do Programa de Interpretação Ambiental adequado para Turismo de Aventura, Interpretação Ambiental e Educação Ambiental.

A Topofilia é um conceito utilizado para compreender qual é o nível de interação do homem com a natureza, a partir dos sentidos, que de certa forma analisa como a natureza desperta emoções no ser humano, sendo assim Yi-Fu Tuan (1980, p.107) define Topofilia como:

\begin{abstract}
A topofilia é um neologismo, útil quando pode ser definida em um sentido mais amplo, incluindo todos os laços afetivos dos seres humanos com o meio ambiente material. A resposta ao meio ambiente pode ser basicamente estética: em seguida, pode variar de o efêmero prazer que se tem de uma vista, até a sensação de beleza, igualmente fugaz, mas muito mais intensa, que é subitamente revelada. A resposta pode ser tátil: o deleite ao sentir o ar, água, terra. Mais permanentes e mais difíceis de expressar, são os sentimentos que temos para com um lugar, por ser o lar, o lócus de reminiscências e o meio de se ganhar a vida. (TUAN, 1980, p.107)
\end{abstract}

Com isso, compreende-se que topofilia está na relação entre paisagem, memória e cultura. Conceito que auxilia também a compreender a preferência por algumas paisagens, como por exemplo, os mirantes que neste trabalho tiveram destaque, isso se justifica pela memória instintiva que carregamos ao longo da evolução humana, a preferir lugares altos com grande visibilidade, sendo possível avistar o inimigo/predador ou até mesmo caça. Sendo assim Tuan ressalta que "Muito do que percebemos tem valor para nós, para a sobrevivência biológica, e para propiciar algumas satisfações que estão enraizadas na cultura.". Em relação a preferência por mirantes, Appleton (apud VASCONCELLOS; HUTZ,2014) se refere a lugares altos, montanhas e mirantes como ambientes de perspectiva, que está relacionada ao instinto de sobrevivência de avistar o predador. Em relação a cavernas o autor se refere a refúgio como instinto de proteção.

\section{Considerações finais}

Constatou-se que foi possível instaurar ações de Percepção Ambiental por meio da realização da Trilha Interpretativa Guiada Bandeirantes da Serra no PNMM. Também, evidenciou-se que a realização TIGBS, bem como, os resultados da presente pesquisa forneceram subsídios para gestão da UCs no que diz respeito ao entendimento da percepção dos visitantes do PNMM. Além disso, permitem o esclarecimento, 
a compreensão da importância da instituição dessa UC, no decorrer da atividade prática em contato a natureza. Destaca-se ainda, a importância da continuidade da realização de Trilhas Interpretativas na UC, para que assim, tornem-se uma ferramenta efetiva de manejo e divulgação do PNMM.

\section{Agradecimentos}

Ao Grupo Bandeirantes da Serra pelo apoio na realização desta pesquisa. Ao antigo Gestor do PNMM Filipe de Moura Martins pela atenção e disponibilidade e a Secretaria Municipal de Meio Ambiente de Santa Maria.

\section{Nota:}

${ }^{1}$ Conjunto das coisas que pode ser reduzido a unidade. Consiste em um enfoque epistêmico utilizado no sec. XIX com o surgimento com conceito de paisagem juntamente com a Ciência Geográfica, consiste no estudo da paisagem como uma totalidade.

\section{Referências}

A declaração do Tirol sobre a boa pratica nos esportes de montanha. "Ampliem seus limites, elevem seus espíritos e almejem o topo". Conferência sobre o Futuro dos Esportes de Montanha, Innsbruck, 2002. Disponível em: http://www.bandeirantesdaserra.org.br/ambiente/Declara\% C3\%A7\%C3\%A30\%20do\%20Tirol.pdf. Acesso em: 18 nov. 2017

ANDRADE, W. J.; ROCHA, R. F. da. Manual de trilhas: um manual para gestores. n 35. São Paulo, IF Sér. Reg, p. 1-74. 2008.

BOADA, M; TOLEDO, V.M. El planeta, nuestrocuerpo. La ecologia, elambientalismo y lacrisis de la modernidade. México: FCE. 2003.

BRASIL. Lei $\mathbf{n} . \mathbf{9 . 9 8 5}$ de 18 de julho de 2000, que regulamenta o art. 225, § $1^{\circ}$, inciso I, II, III e VII da Constituição Federal, instituiu o Sistema Nacional de Unidades de Conservação da Natureza e dá outras providências. Presidência da República - Casa Civil, Brasília, DF, 18 jul. 2000. Disponível em: <http://www.planalto.gov.br/ccivil 03/leis/l9985.htm>. Acesso em: 20 abr. 2016.

CASSETI, V. Geomorfologia. [S.I.]: [2005]. Disponível em: $<$ http://www.funape.org.br/geomorfologia/>. Acesso em 09 de dez de 2016.

CÓDIGO BRASILEIRO DE ÉTICA NA ESCALADA. 1 Seminário Paranaense em março de 1993. Disponível em: http://www.bandeirantesdaserra.org.br/ ambiente/C\%C3\%B3digo\%20Brasileiro\%20de\%20\%C3\%A9tica\%20na\%20e scalada.pdf . Acesso em: 18 nov.2017.

DIAS, A. C.; MOURANETTO, B. V.; MARCONDES, M. A. P. Trilha interpretativa do rio Taquaral - Parque Estadual de Carlos Botelho. Bol. Edição especial.Técn. IF,p. 11-32.v. 40-A. 1986. 
GEOPROPEC Geologia e Projetos Ambientais Ltda. Plano de Manejo do Parque dos Morros. Santa Maria, RS. p.274, 275. V3. 2013 A.

GEOPROPEC Geologia e Projetos Ambientais Ltda. Plano de Manejo do Parque dos Morros. Santa Maria, RS.p. 282. V3. 2013 B.

GEOPROPEC Geologia e Projetos Ambientais Ltda. Plano de Manejo do Parque dos Morros. Santa Maria, RS.p.38. V3. 2013 C.

GERS. Governo do Estado do Rio Grande do Sul. 2008. Projeto Conservação da Biodiversidade como Fator de Contribuição Desenvolvimento do Estado do Rio Grande do Sul. Projeto RS Biodiversidade. Secretaria do Planejamento e Gestão. Disponível em: $<$ http://www.biodiversidade.rs.gov.br/arquivos/12156251430 Projeto Conser vacao da Biodiversidade com Fator de Contribuicao ao Desenvolviment o do Estado do Rio Grande do Sul.pdf>. Acesso em: 10 nov. 2017.

GERS. Ministério do Meio Ambiente. Avaliação e ações prioritárias para a conservação da biodiversidade da Mata Atlântica e Campos Sulinos. 2000. Conservation International do Brasil, Fundação SOS Mata Atlântica, Fundação Biodiversitas, Instituto de Pesquisas Ecológicas, Secretaria do Meio Ambiente do Estado de São Paulo, SEMAD/Instituto Estadual de Florestas-MG. Brasília: MMA/ SBF,. 40 p.

GRUPO BANDEIRANTES DA SERRA. Fundação. Disponível em: http://www.bandeirantesdaserra.org.br/quemsomos.asp. Acesso em 29 de novembro de 2017.

IBGE. Instituto Brasileiro de Geografia e Estatística. Série Manuais Técnicos em Geociências, Rio de Janeiro. IBGE, n. 1. 2 ed. 2012.

IBGE. Instituto Brasileiro de Geografia e Estatística. 2017. Panorama, Santa Maria, RS. Disponível em: https://cidades.ibge.gov.br/brasil/rs/santamaria/panorama. Acesso em: 14 de setembro de 2018.

IKEMOTO, S.M. As Trilhas Interpretativas e sua relevância para promoção da conservação: Trilha do Jequitibá, Parque Estadual dos Três Picos (PETP), RJ. 121f. Dissertação (Curso de Pós-Graduação em Ciência Ambiental) Universidade Federal Fluminense. 2008.

LÖBLER C. A; SCOTTI A.A.V.; M.K. WERLANG. Contribuição à delimitação dos biomas Pampa e Mata Atlântica no município de Santa Maria, RS. Revista Eletrônica em Gestão, Educação e Tecnologia Ambiental. Santa Maria, v. 19 , n. 2, p. 1250-1257 Revista do Centro de Ciências Naturais e Exatas - UFSM. 2015.

MARCHIORI, J. N. C. A Vegetação em Santa Maria. Ciência \& Ambiente, Santa Maria, n.38, p. 91-112. 2009.

MARCUZZO, R.; PAGEL, S. M.; CHIAPPETTI, M. I. S. A Reserva da Biosfera da Mata Atlântica no Rio Grande do Sul- Situação atual, ações e perspectivas. Conselho Nacional da Reserva da Biosfera da Mata Atlântica. Secretaria de Estado do Meio Ambiente do Estado de São Paulo. Companhia de Tecnologia Ambiental. Série Cadernos da Reserva da Biosfera da Mata Atlântica. São Paulo, n. 11, 61 p. 1998. 
NOVO, M.V. El desarrollosustenible. Sudimención ambiental y educativa. Madrid: Pearson Educación. 2006.

PROJETO DOCES MATAS. Manual de Introdução à Interpretação Ambiental. Belo Horizonte: IEF: IBAMA.Fundação Biodiversitas. 2002.

RIO GRANDE DO SUL. DECRETO № 38.814, DE 26 DE AGOSTO DE 1998. Regulamenta o Sistema Estadual de Unidades de Conservação SEUC e dá outras providências. Disponível em: http://www.al.rs.gov.br/ legis/M010/M0100099.ASP?Hid Tipo=TEXTO\&Hid TodasNormas=6124\&hT exto=\&Hid IDNorma=6124. Acesso em 18 de novembro de 2017.

ROCHA, C. H. B. Aplicação no Parque Estadual de Ibitipoca/MG. Juiz de Fora: COBRAC. 2006.

ROSS, J. L. S. Classificação do Relevo Brasileiro. 1985. In. ROSS, J. L. S. (Org). Geografia do Brasil. São Paulo.5 ed. rev. e ampl: Ed. USP, p. 52. 2005.

SANTA MARIA, 2016 A Decreto Executivo n. 0012, de 11 fevereiro de 2016. Dispõe sobre Permissão de Uso, a título precário e gratuito, da área do Parque do Morro e dá outras providências. Secretaria de gestão e Modernização administrativa. Superintendência de administração. Santa Maria. 2016.

SANTA MARIA, 2016 B. Decreto Municipal № 74, de 6 de setembro de 2016. Cria o Parque Natural Municipal dos Morros- PNMM, dispõe sobre os seus limites, zona de amortecimento e dá outras providências. Santa Maria, RS.

SANTOS, M; FLORES, M; ZANIN, E. Trilhas interpretativas como instrumento de interpretação, sensibilização e educação ambiental na APAE de Erechim/RS. Revista Eletrônica de Extensão da URI. 2011.

SECRETARIA DO MEIO AMBIENTE. Instituto Florestal. Manejo de Trilhas: Um Manual para Gestores. São Paulo: IF Série e Registros, n.35. 2008.

SILVA, D.M.2012. A Caracterização da Interpretação Ambiental pelo conteúdo das mensagens: analise da atividade de um guia do Parque Estadual Mata dos Godoy (Londrina/PR.,90f. Dissertação (mestrado em Ciências e Educação Matemática). Universidade Estadual de Londrina, 2012. Disponível em http://www.iap.pr.gov.br/arquivos/File/Pesquisa\% 20em\%20UCs/Autorizacao e Projetos 2014/projeto 001.pdf. Acesso em 20 de set. De 2016.

THOMAS, B.L; NASCIMENTO, D.B; KORMANN, T.C; FOLETO, E.M. Zoneamento ambiental como subsídio à elaboração do plano de manejo da reserva particular do patrimônio da fundação MO'Ã em Itaara (RS). Londrina, 2011. Disponível em http://www.uel.br/revistas/uel/ index.php/geografia. Acesso em 7 de julho de 2016.

TILDEN, F. Interpreting Our Heritage. The University of North Carolina Press, Chapel Hill. North Carolina. 1957.

TORRES, P.S.U; BASSOLS, N.B. Historia y paisaje. Explorando um concepto geográfico monista. Andamios, n. 10, p.227-252.v. 5. 2009. 
TUAN, Y. F. (trad. Lívia de Oliveira). Topofilia: Um Estudo da Percepção, Atitudes e Valores do Meio Ambiente. São Paulo: Difel. 1980.

VASCONCELLOS, J. M. de O. Avaliação da eficiência de diferentes tipos de trilhas interpretativas no Parque Estadual Pico do Marumbi e Reserva Natural Salto Morato-PR. Natureza \& Conservação, Curitiba, n. 2, p. 4857v. 2. 2004.

VASCONCELLOS, S.J; Hutz, C.S. Abertura à Experiência e Preferência por Paisagens Naturais: uma Abordagem Evolucionista. Psico, Porto Alegre, PUCRS, n. 4, pp. 535-540v. 45. 2014.

Marina Deon Ferrarese: Universidade Federal de Santa Maria, Santa Maria, RS, Brasil.

E-mail: marinadeonbio@gmail.com

Link para o currículo Lattes: http://lattes.cnpq.br/7280272106698167

Letícia Ramires Corrêa: Universidade Federal de Santa Maria, Santa Maria, RS, Brasil.

E-mail: leticiarcorrea@gmail.com

Link para o currículo Lattes: http://lattes.cnpq.br/3357786530501748

Guilherme Lul da Rocha: Secretaria Municipal do Meio Ambiente, Santa Maria, RS, Brasil.

E-mail: rocha@bandeirantesdaserra.org.br

Link para o currículo Lattes: http://lattes.cnpq.br/9597157957826833

Rafael Camilo Ribeiro: Universidade Federal de Santa Maria, Santa Maria, RS, Brasil.

E-mail: rafael@bandeirantesdaserra.org.br

Link para o currículo Lattes: Não apresenta.

Data de submissão: 11 de janeiro de 2019

Data de recebimento de correções: 16 de abril de 2019

Data do aceite: 16 de abril de 2019

Avaliado anonimamente 